\title{
Relationships Between Young Men's Health-Related Behaviour, Psychological Distress, Physical Education and Sports Experience
}

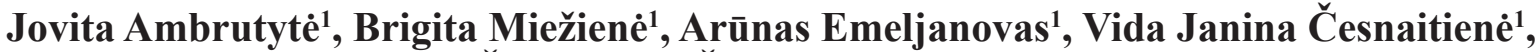 \\ Daiva Vizbaraitè ${ }^{1}$, Renata Žumbakytè-Šermukšniené ${ }^{2}$ \\ Lithuanian Sports University', Kaunas, Lithuania \\ Lithuanian University of Health Sciences², Kaunas, Lithuania
}

\begin{abstract}
Background. Negative health-related behaviours among young adults are common worldwide. Most of young males are physically inactive, have poor diets, drink a lot of alcohol or smoke, and such behaviour causes physical and mental health disorders (Aubert et al., 2018). Nowadays more mental health problems are diagnosed among young people than a decade. Researchers are trying to determine the causes of harmful behaviour in adults, but the impact of previous physical education on further health-related behaviours in adults has not been studied.

Methods. Physical activity, alcohol consumption and cigarette smoking was evaluated according to the 2008 US Department of Defense Survey of Health Related Behaviours (Bray et al., 2009). Adherence to a healthy eating pattern was evaluated using the Mediterranean diet adherence screener (MEDAS). Psychological distress was assessed using the six-item Kessler scale (Kessler et al., 2003).

Results. Nearly half of young adults were physically inactive, ate poorly, had harmful habits, one of ten had high psychological distress. Two thirds of the respondents participated in sports in childhood, $61 \%$ of young people liked the physical education lessons, $44 \%$ of them attended every PE lesson. Lower distress was significantly associated with better nutrition, higher physical activity, lower alcohol consumption, and smoking. Also, significant associations were found between higher alcohol consumption and more frequent smoking. Higher incomes, younger age, better perception and attendance of PE classes in the past, active lifestyle in childhood and adulthood are the predictive factors of more favourable health-related behaviours and better mental health.

Conclusions. Harmful health-related behaviours are prevalent among young adults, one of tenth has high psychological distress. Although the majority of young adults were active in childhood, the percentage of active adults decreases significantly. More favourable health-related behaviours are related to less distress. Better economic status, better PE experiences in childhood, sports activities in adulthood lead to better health-related behaviours and less distress.
\end{abstract}

Keywords: young adults, health-related behaviours, mental health, physical education.

\section{INTRODUCTION}

$\mathrm{T}$ The age group of young adults is one of the most vulnerable stages of life, which includes persons from 18 to 34 years (Unick et al., 2017). Young people in this age group are reported to have low dietary variety, nutrient deficiencies, high risk of metabolic syndrome, and a sedentary lifestyle (Akseer, Al-Gashm, Mehta, Mokdad, \& Bhutta, 2017). In Europe, $46 \%$ of adults do not reach recommended physical activity level and the percentage of physically active people is steadily declining across Europe, while Lithuanian young adults are among the least physically active in the European Union (Mayo, Miksche, Attwell-Pope, \& Gawryluk, 2019; Kalman et al., 2015). Another study reveals that only $39 \%$ of the population participate in physical activity regularly, and the 
remaining $61 \%$ does not exercise at all or does not do it enough (Dhivyadharshini \& Mohanraj, 2019). The results of a study conducted in Lithuania reveal that only $7 \%$ of young people fully adhere to the recommendations of healthy eating (Mieziene et al., 2020). Almost every second young person consumes fast food (Jacob et al., 2020). Most of the youth do not consume enough fruits and vegetables (Nour et al., 2017). Baburin (2020) found that young adults consumed alcohol and it was more harmful than other age groups.

Adverse health-related behaviours are leading to an increasing number of health problems among young people. The physical capacity of young people today is inferior than that in previous generations (Aubert et al., 2018). More than half of young adults have overweight (Ogden, Carroll, Kit, \& Flegal, 2014). Changes in blood glucose, blood pressure, and musculoskeletal system have been found (Mullane et al., 2017). Harmful habits, such as smoking, affect endothelial functions, oxidative processes, platelet functions, fibrinolysis, inflammatory processes, lipid oxidation, and vasomotor function (Piepoli et al., 2016). Also, more and more studies confirm the association of sedentary lifestyle with negative mental health outcomes (Hoare, Milton, Foster, \& Allender, 2016). A meta-analysis conducted by Pedersen and other scientists (2020) revealed that smoking, regular alcohol consumption, physical inactivity, and a low-calorie diet posed a risk to mental health. Teasdale and co-authors (2020) found that people with poorer nutritional knowledge faced more severe mental disorders. A recent report suggests that decreased insulin levels in the brain affect dopamine metabolism and excretion, leading to mood disorders (Cai et al., 2018). In order to prevent health-related behaviour from harming health, it is first necessary to identify the factors that influence such behaviour.

Researchers recognize that adult behaviour can be determined by habits formed in childhood. According to Dadel (2014), attitudes towards physical activity formed in youth can persist throughout life. Children's attitudes towards a healthy lifestyle are shaped not only by parents or friends, but also by teachers and coaches, so it is worth paying attention to organized physical activity. It is important to emphasize that organized physical activity also includes physical education, which develops the attitudes and abilities of students' health-enhancing lifestyles and habits of regular physical activity throughout the life course (Ward et al., 2008). Recent studies in as many as 54 countries have shown that $55.2 \%$ of teenagers attend physical education classes only once a week, and almost $20 \%$ of them have never been involved in physical education. It was also found that attendance of PE classes deteriorated with age, adolescents aged 13-14 years were more likely to attend physical education classes than adolescents aged 15-18 (Martins et al., 2020).

Scientific literature usually analyses the influence of sociodemographic, family, friends, psychological factors on health-related behaviour choices of young adults, but the impact of physical education on the later behaviour of young adults has not been studied. It is important to find out how young adults value the quality of physical education and how often they attended this classes because this experience can be a very important motivating factor in promoting a further lifelong healthy lifestyle. Lack of sports experience, higher body mass index (BMI), and unfavourable economic situation can also pose additional barriers to healthier behaviours.

The aim of the study was to evaluate the health-related behaviours, sports experiences, PE experiences, psychological distress, sociodemographic and BMI factors of young adult men and to analyse their relationships. The obtained results will reveal which factors most hinder the development of a healthy lifestyle among young people. Perhaps, in order to change adult behaviour, one should first start with physical education or the improvement of the whole education system.

The object was relationships between healthrelated behaviours and psychological health with physical education and sports experience.

Hypothesis of the study maintained that men with better physical education and sports experience in childhood would have better health-related behavioural habits and mental health in adulthood.

\section{METHODS}

Organization of the study. This quantitative study was conducted in 2018, June-October, in four centres for military recruitment (Kaunas, Vilnius, Klaipėda and Panevėžys). The approval of the research ethics (No. SMTEK-62, 2020) was granted by the Research Ethics Committee of the Lithuanian Sports University. The study was conducted in accordance with the regulations 
outlined in the Declaration of Helsinki in 1974, revised in 2013. Respondents were introduced to the course of the study and signed a written consent form to participate in the study before participating in the study.

Participants. In 2018, from the official list of 10340 conscripts (209 of them were females), this study included 1243 young adult men. The participants were aged 19-26 years and their mean age was $22.50 \pm 2.43$ years.

Research methods. Physical activity. To assess the physical activity of the participants in this study, we used the 2005 U.S. Department of Defense survey on health-related behaviours (Bray et al., 2009). Study participants were asked, "How often did you do each of these leisure activities in the last 7 days?". Participants were also asked, "During the past 7 days of engaging in leisure-time physical activity, how long did you typically perform each of these activities?". In this study, we evaluated the physical activity of the previous 7 days. In addition, instead of using categorical answers to each question (such as "5 or 6 days" and "at least 20 minutes"), we provided the ability to write the exact number of days, hours, and/or minutes per day. Total physical activity was measured by the number of minutes spent. Participants whose physical activity was less than $2.5 \mathrm{~h}$ per week were coded as not meeting health-related physical activity requirements, and participants whose physical activity was less than or equal to $2.5 \mathrm{~h}$. per week were marked as meeting the requirements for health-related physical activity.

Nutrition. Nutrition was assessed by presenting claims based on the World Health Organization's Healthy Eating Recommendations and the corresponding Mediterranean Diet Questionnaire (Martınez-Gonzalez et al., 2012). The questions sought to determine the type of fat most commonly consumed, the amount of olive oil consumed, the amount of animal fat, the frequency and amount of fruit, vegetables, meat, seafood, sweet drinks, nuts, and confectionery. The MEDAS score was divided into three categories: $\leq 7$ showed low adherence, $8-9$ moderate adherence, and $\geq 10$ full adherence to the Mediterranean diet.

Alcohol consumption was measured by the number of occasions on which alcohol was consumed in the last month; by type and quantity of alcoholic beverages consumed; by the number of days per month when more than 5 units of any alcohol were consumed (e.g., beer cans, bottles
$(0.33 \mathrm{ml})$, wine glasses $(150 \mathrm{~g})$, etc.). The statements were based on a study of health-related behaviours by U.S. Department of Defense servicemen (Bray et al., 2009). Subjects were divided into three groups according to the number of standard alcohol units consumed: non-drinkers, those with a moderate health risk (less than 20 units/month) and those with a high health risk (more than 20 units/month).

Cigarette smoking was assessed by statements identifying whether a person smoked at all, whether he or she smoked in the past 30 days, and how many cigarettes he smoked during that time. Subjects were divided into three categories: 1) non-smokers at all, 2) smokers (less or more than 20 cigarettes per day).

Distress was measured using a 6-statement Kessler scale (Kessler et al., 2003). The statements assessed the participants' nervousness, feeling of hopelessness, anxiety, depression, lack of strength and feeling of worthlessness during the last 30 days. The answers ranged from 0 ("I feel this way all the time") to 4 ("I never feel this way"). According to the total distress score, the participants were divided into two groups: those with low distress (0-12 points) and those with high distress (13 and more points).

Physical education and sports experience. The experience of physical education at school was assessed in terms of class attendance and feedback from respondents. Respondents answered the questions: how do you assess previous physical education lessons? (liked; neither liked nor disliked; disliked) What was your attendance at physical education classes? (100\%; 75\%; 50\%; 25\%). Sports experience was assessed in childhood and adulthood. Respondents answered the questions: did you play sports as a child? Are you currently exercising?

Statistical analysis. The data was analysed using SPSS version 24 statistics package. Categorical variables were presented as frequencies and percentages. The relationships between independent continuous variables were examined using Pearson correlational analysis because all scaled variables had a normal distribution. Logistic regression analysis was used to identify relationships between independent variables (covariates, health behaviours, and psychological distress) by producing odds ratios (ORs) and $95 \%$ confidence intervals (95\% CIs). Statistical significance was set at $p<.05$. 


\section{RESULTS}

According to the World Health Organization, the recommended (2.5 hours/week) level of physical activity is reached by $54 \%$ of young adult men. Although $78 \%$ respondents stated that they exercised at a younger age, but being, adult only $23 \%$ of respondents regularly participated in physical activity. While investigating the recalled perception of physical education in school, it was found that the majority of young people $(61 \%)$ enjoyed physical education lessons and only $9 \%$ did not like them, $30 \%$ had no opinion. Almost half of the respondents stated that they attended every physical education lesson, 34\% said they attended more than half of the lessons, $14 \%$ attended every second lesson, and $8 \%$ of respondents acknowledged extremely low attendance at classes. As nutrition is concerned, 52\% of young adults' diet is poor and does not meet the recommendations. It was found that more than half of young people (64\%) smoked, and even more young people $(68 \%)$ consumed alcohol, which was harmful. Examining the level of distress, it was found that $11 \%$ of young adults felt high levels of distress. Analysing the family income, it was found that more than half of the respondents grew up in middle-income families, $21 \%$ received higher than average income, and $10 \%$ lived affluently, $7 \%$ said they had a low family income. Examining the body composition of young adults, we found that $27 \%$ of the respondents were overweight, and $8 \%$ were obese.

The results presented in Table 1 reveal statistically significant associations between diet, smoking and distress. Young people with good or satisfactory diets smoked less frequently and experienced lower distress. It was also found that lower distress was significantly associated with higher physical activity, lower alcohol consumption, and smoking. Significant associations were also found between higher alcohol consumption and more frequent smoking.

The results presented in Table 2 revealed that higher physical activity level was associated with the younger age of young men. Higher physical activity also predicted better assessment of PE classes. It was established that if young people were currently exercising regularly, their total physical activity was three times higher than that of young people who were not currently exercising. Sociodemographic, BMI, PE, and regular exercise factors together explained $12.2 \%$ of dispersion of physical activity.

Healthier diets were more often (43\%) promoted by individuals who had favourable attitudes towards the quality of PE lessons and almost three times more often by individuals who currently exercised regularly. Sociodemographic, BMI, PE and regular exercise factors together explained $9.3 \%$ of satisfactory and recommended nutrition dispersion.

Individuals who rated $\mathrm{PE}$ lessons better did not smoke $54 \%$ more often than those who had poorer feedback on PE lessons. Also, individuals who did sports regularly smoked less frequently than those who did not exercise or did it irregularly. However, it was found that individuals who exercised in childhood currently smoked more often. Sociodemographic, BMI, PE, and regular exercise factors together explained $7.6 \%$ of non-smoking dispersions.

The results presented in this table revealed that moderate alcohol consumption was associated with younger age of young men and PE attendance at school. The body mass index and the family income did not predict alcohol consumption. Younger men consumed less alcohol than the older ones, and attended PE classes better. Sociodemographic, $\mathrm{BMI}, \mathrm{PE}$, and regular exercise factors together

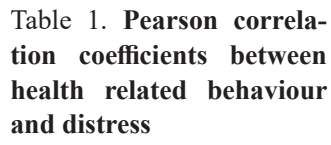

Note. $* * p<.01$

\begin{tabular}{|l|c|c|c|c|c|}
\hline Correlations & Nutrition & $\begin{array}{c}\text { Physical } \\
\text { activity }\end{array}$ & $\begin{array}{c}\text { Alcohol } \\
\text { consumption }\end{array}$ & Smoking & Distress \\
\hline Nutrition & 1 & .052 & -.062 & $-.164^{* *}$ & $-.210^{* *}$ \\
\hline Physical activity & & 1 & -.007 & .018 & $-.092^{* *}$ \\
\hline Alcohol consumption & & & 1 & $.238^{* *}$ & $.131^{* *}$ \\
\hline Smoking & & & & 1 & $.132^{* *}$ \\
\hline Distress & & & & & 1 \\
\hline
\end{tabular}


Table 2. Associations between sports experiences, PE experiences, psychological distress, sociodemographic, BMI factors and healthrelated behaviours in the logistic regression model

\begin{tabular}{|c|c|c|c|c|c|}
\hline Variables & $\begin{array}{c}\text { Adequate Physical } \\
\text { activity }\end{array}$ & $\begin{array}{l}\text { Healthier } \\
\text { nutrition }\end{array}$ & $\begin{array}{c}\text { Non- } \\
\text { smoking }\end{array}$ & $\begin{array}{l}\text { Lower alcohol } \\
\text { consumption }\end{array}$ & $\begin{array}{l}\text { Lower } \\
\text { distress }\end{array}$ \\
\hline Income & $\begin{array}{c}1.109 \\
(0.960-1.281)\end{array}$ & $\begin{array}{c}1.208 \\
(0.991-1.473)\end{array}$ & $\begin{array}{c}0.961 \\
(0.829-1.114)\end{array}$ & $\begin{array}{c}0.926 \\
(0.763-1.124)\end{array}$ & $\begin{array}{c}1.834 \\
(1.380-2.436)\end{array}$ \\
\hline BMI (overweight) & $\begin{array}{c}1.179 \\
(0.918-1.515)\end{array}$ & $\begin{array}{c}1.079 \\
(0.772-1.509)\end{array}$ & $\begin{array}{c}1.136 \\
(0.882-1.461)\end{array}$ & $\begin{array}{c}0.957 \\
(0.687-1.334)\end{array}$ & $\begin{array}{c}1.074 \\
(0.701-1.644)\end{array}$ \\
\hline BMI (obese) & $\begin{array}{c}0.721 \\
(0.479-1.084)\end{array}$ & $\begin{array}{c}1.280 \\
(0.762-2.149)\end{array}$ & $\begin{array}{c}1.359 \\
(0.902-2.047)\end{array}$ & $\begin{array}{c}0.738 \\
(0.401-1.360)\end{array}$ & $\begin{array}{c}0.702 \\
(0.391-1.261)\end{array}$ \\
\hline Age & $\begin{array}{c}0.941 \\
(0.906-0.977)\end{array}$ & $\begin{array}{c}1.005 \\
(0.960-1.052)\end{array}$ & $\begin{array}{c}1.016 \\
(0.984-1.049)\end{array}$ & $\begin{array}{c}0.913 \\
(0.860-0.970)\end{array}$ & $\begin{array}{c}0.947 \\
(\mathbf{0 . 9 0 3 - 0 . 9 9 3 )}\end{array}$ \\
\hline Evaluation of PE & $\begin{array}{c}1.503 \\
(1.230-1.837)\end{array}$ & $\begin{array}{c}1.432 \\
(1.080-1.900)\end{array}$ & $\begin{array}{c}0.849 \\
(0.689-1.046)\end{array}$ & $\begin{array}{c}1,180 \\
(0.897-1.553)\end{array}$ & $\begin{array}{c}1.851 \\
(1.370-2.501)\end{array}$ \\
\hline Attendance of PE & $\begin{array}{c}1.126 \\
(0.982-1.292)\end{array}$ & $\begin{array}{c}0.960 \\
(0.795-1.160)\end{array}$ & $\begin{array}{c}1.543 \\
(1.328-1.792)\end{array}$ & $\begin{array}{c}1.261 \\
(1.035-1.535)\end{array}$ & $\begin{array}{c}1.262 \\
(1.024-1.554)\end{array}$ \\
\hline Sports in childhood & $\begin{array}{c}0.915 \\
(0.691-1.211)\end{array}$ & $\begin{array}{c}0.975 \\
(0.668-1.424)\end{array}$ & $\begin{array}{c}0.656 \\
(0.491-0.875)\end{array}$ & $\begin{array}{c}1.088 \\
(0.734-1.613)\end{array}$ & $\begin{array}{c}0.926 \\
(0.606-1.416)\end{array}$ \\
\hline Adulthood sports & $\begin{array}{c}3.027 \\
(2.268-4.04)\end{array}$ & $\begin{array}{c}2.986 \\
(2.035-4.381)\end{array}$ & $\begin{array}{c}2.158 \\
(1.656-2.812)\end{array}$ & $\begin{array}{c}1.146 \\
(0.795-1.651)\end{array}$ & $\begin{array}{c}1.947 \\
(1.080-3.510)\end{array}$ \\
\hline Negelkerke $R^{2}$ & 0.132 & 0.093 & 0.076 & 0.048 & 0.139 \\
\hline
\end{tabular}

Note. Table presents odds ratios (ORs) and 95\% confidence intervals (95\% CIs). Boldface indicates significant values $(p<.05)$.

explained almost $5 \%$ of dispersions of moderate alcohol consumption.

From the results presented in Table 2, it can be stated that family income, age, assessment of PE school classes and attendance in sports activities were associated with lower distress. Higher income young people $(83 \%)$ were less likely to experience distress, as well as $6 \%$ of younger individuals who experienced less distress; $85 \%$ of young people who rated PE lessons at school better, and 26\% of young people who had better attendance of PE classes felt less distress than those who rated and attended PE lessons worse. Also, it was found that people who currently participated in sports activities, were by $94 \%$ less likely to experience distress than non-adequately physically active young adults. Sociodemographic, BMI, PE, and regular exercise factors together explained nearly $14 \%$ of dispersions of less distress experience.

\section{DISCUSSION}

The primary objective of this study was to elucidate the predictors of health-related behaviours and distress. To achieve the goal, the prevalence of young adult behaviours and the amount of distress experienced were first determined.

The study revealed that health-related behaviours were not widespread among Lithuanian youth. More than half of young adults promoted harmful alcohol consumption and regular smoking, and their diets were described as poor. It was found that the majority of young people did not exercise regularly (77\%) and did not reach the recommended activity level (46\%). According to a meta-analysis by Guthold and other researchers (2018), physical inactive adults in Lithuania comprise $30 \%$, and the highest percentage of physically inactive adults was found in Latin America, Southeast Asia and Central Europe, where more than $50 \%$ of adults are physically inactive. Researchers have found links between physical activity, BMI, chronic diseases, health status, and psychological barriers (Seo, Kang, \& Jeon, 2016). According to Koa and Parkb (2020), greater involvement in physical activity was predicted by male gender, better economic status, and perceived better quality of life, as well as physical, psychological, and environmental factors.

Discussing the situation of physical education, it was found that $78 \%$ of young adult men said 
they played sports at school and attended physical education classes well. A study in the United States found that attendance in physical education classes was much lower, only $15 \%$ of primary and $9 \%$ of secondary school students attended each physical education lesson (Katzmarzyk et al., 2018). It was observed that adolescents who attended physical education classes more often achieved high intensity of movements and spent more time actively after school (Silva, Chaput \& Tremblay, 2019).

A study of eating habits found that $48 \%$ our young compatriots were eating satisfactorily or were following healthy eating recommendations. Young people did not consume enough olive oil, nuts, fish, seafood, legumes, but they consumed too much red meat (Mieziene et al., 2020). In warmer climates, the number of people following this diet is higher, for example, in Spain it is 15.5\% (Carlos, Bernabéu \& Terresa 2020). According to Niles et al. (2020), the diversity of food consumed is related to the country's climate. The results of a study by Novak et al. (2017) showed that higher adherence to the Mediterranean diet was associated with better assessment of health, socioeconomic status, and physical activity of older students, while lower adherence to the Mediterranean diet was associated with female gender, higher BMI, psychological experiences, and sedentariness.

Researchers studying harmful habits in young people have found that alcohol consumption correlates with age groups, with the highest alcohol consumption observed in the young adult age group (Baburin et al., 2020). National study in the Americas showed that $9 \%$ of adolescents and $57 \%$ of young adults consumed alcohol in the past month (Substance Abuse and Mental Health Services Administration, 2017). Our study found a higher percentage $(68 \%)$ of young people who consumed alcohol. Another study in the Baltic and Scandinavian countries found that alcohol consumption was highest in Latvia and Lithuania and lowest in the Nordic countries. According to scientists, it may depend on higher density of retail alcohol stores and longer opening hours in the Baltics countries (Pärna, 2020).

Researchers note that cigarette smoking has been on a declining trend in recent years, and is being replaced by the growing popularity of flammable and non-flammable electronic products (Wang et al., 2018). Despite these changes, the market for tobacco products continues to be dominated by flammable cigarettes (Jamal et al., 2018). In addition, Khouja and colleagues (2020) found a link between the use of electronic smoking devices and subsequent cigarette smoking. According to the World Health Organization, the highest percentage $(46.7 \%)$ of cigarette smokers is recorded in the Pacific Islands, followed by Europeans (38.7\%) and the lowest prevalence in Africa at $17.7 \%$. (WHO, 2018). According to the survey, Lithuanian youth exceeds both the European and world average, as the number of smokers is extremely high - it reaches $64 \%$. Other authors also emphasize the importance of adolescence and argue that smoking onset and persistence were significantly associated with family cigarette use habits and the influence of friends (Taheri Ghorbani, Salehi, \& Sadeghnia, 2015).

Another task of the study was to determine the relationships between health-related behavioural variables and the psychological health of young adult men. It has been found that poorer diet, lower physical activity, and harmful habits have a significant impact on greater distress. According to researchers, less distress occurs in those individuals who are active and have a social connection (Anderson \& Fowers, 2020). Adherence to the Mediterranean diet is also associated with fewer depressive symptoms, and many studies have relied on its principles for managing depression (Altun, Brown, Szoeke, \& Goodwill, 2019). A study of the association of psychological health with the components of the Mediterranean diet found that high fruit and vegetable consumption was associated with a lower risk of depression and anxiety (Sadeghi, Keshteli, Afshar, Esmaillzadeh, \& Adibi, 2019). The influence of harmful habits on poorer psychological condition has also been proven. Balogun and colleagues (2014) found that the incidence of distress increases with regular alcohol consumption. Another study found an association between the lack of physical activity and increased distress, also predicted by gender, sleep disturbances, perceived health, fast food, and fresh fruit consumption (Uddin, Burton, \& Khan, 2020).

In order to achieve the aim of the study, it was found that socio-demographic, PE and sports experience factors had a significant impact on physical activity, diet, harmful habits and psychological health. The analysis of results revealed that better assessment of PE lessons led to the more favourable health-related behaviours and lower distress, and better attendance of $\mathrm{PE}$ 
lessons was associated with less frequent alcohol use, non-smoking, and lower distress. There were also associations between younger age, active lifestyle in adulthood, higher physical activity and less frequent harmful habits, it was also found that lower levels of distress were significantly affected by the better economic situation.

The study has some limitations. We used a cross-sectional design, and no causal inferences can be drawn. It remains unclear whether the unhealthy behaviours were the causes or the consequences of the health outcomes. Longitudinal studies are needed to evaluate the direction of, and interactions between, the associations demonstrated here. Another limitation is that we did not include objective measures of physical and mental health. Further research should investigate for more comprehensive and larger-scale studies examining the impact of physical education on adult healthrelated behaviours.

\section{CONCLUSION}

In conclusion, it can be stated that healthrelated behaviours of young adults in Lithuania are unsatisfactory because about half of them are physically inactive, eat unhealthily, are engaged in harmful habits, and one in ten has high psychological distress. Health-related behaviours and distress are predicted by a variety of sociodemographic and psychological factors as well as previous experience in physical education at school.

The findings show that in order to promote physical activity in society, more attention should be paid to improving the quality of physical education and health education programs in schools.

\section{REFERENCES}

Akseer, N., Al-Gashm, S., Mehta, S., Mokdad, A., \& Bhutta, Z. A. (2017). Global and regional trends in the nutritional status of young people: A critical and neglected age group. Annals of the New York Academy of Sciences, 1393(1), 3-0. https://doi.org/10.1111/ nyas. 13336

Altun, A., Brown, H., Szoeke, C., \& Goodwill, A. M. (2019). The Mediterranean dietary pattern and depression risk: A systematic review. Neurology, Psychiatry and Brain Research, 33, 1-10. https://doi.org/10.1016/j. npbr.2019.05.007

Anderson, A. R., \& Fowers, B. J. (2020). Lifestyle behaviors, psychological distress, and well-being: A daily diary study. Social Science \& Medicine, 263, 113263. https://doi.org/10.1016/j.socscimed.2020.113263

Aubert, S., Barnes, J. D., Abdeta, C., Nader, P. A., Adeniyi, A. F., Aguilar-Farias, N., ... \& Chang, C. K. (2018). Global matrix 3.0 physical activity report card grades for children and youth: Results and analysis from 49 countries. Journal of Physical Activity and Health, 15(2), 251-273. https://doi.org/10.1123/jpah.2018-0472

Baburin, A., Reile, R., Veideman, T., \& Leinsalu, M. (2020). Age, Period and Cohort Effects On Alcohol Consumption In Estonia, 1996-2018. Alcohol and Alcoholism, 45(4), 115-129. https://doi.org/10.1093/ alcalc/agaa115

Balogun, O., Koyanagi, A., Stickley, A., Gilmour, S., \& Shibuya, K. (2014). Alcohol consumption and psychological distress in adolescents: A multi-country study. Journal of Adolescent Health, 54(2), 228-234. https://doi.org/10.1016/j.jadohealth.2013.07.034

Bray, R. M., Pemberton, M. R., Hourani, L. L., Witt, M., Olmsted, K. L., Brown, J. M., ... \& Scheffler, S. (2009). Department of Defense survey of health related behaviors among active duty military personnel. Research triangle INST (RTI) research triangle park NC. Cai,W., Xue, C., Sakaguchi, M., Konishi, M., Shirazian,A., Ferris, H. A., ... \& Kahn, C. R. (2018). Insulin regulates astrocyte gliotransmission and modulates behavior. The Journal of Clinical Investigation, 128(7), 2914-2926. https://doi.org/10.1172/JCI99366

Carlos, M., Elena, B., \& Teresa, I. M. (2020). Are adherence to the Mediterranean diet, emotional eating, alcohol intake, and anxiety related in university students in Spain? Nutrients, 12(8), 2224. https://doi.org/10.3390/ nu12082224

Dadelo, S. (2014). Motivational characteristics of Lithuanian students' in physical education. Fundamental and Applied Kinesiology - Steps Forward, 1, 707-711.

Dhivyadharshini, J., \& Mohanraj, K. G. (2019). Knowledge, awareness, prevalence, and frequency of daily physical activity in young adults of the present generation. Drug Invention Today, 12(9).

Guthold, R., Stevens, G. A., Riley, L. M., \& Bull, F. C. (2018). Worldwide trends in insufficient physical activity from 2001 to 2016: A pooled analysis of 358 population-based surveys with 1.9 million participants. The Lancet Global Health, 6(10), 1077-1086. https:// doi.org/10.1016/S2214-109X(18)30357-7

Hoare, E., Milton, K., Foster, C., \& Allender, S. (2016). The associations between sedentary behaviour and mental health among adolescents: a systematic review. International Journal of Behavioural Nutrition and Physical Activity, 13(1), 108. https://doi.org/10.1186/ s12966-016-0432-4

Jacob, L., Stubbs, B., Firth, J., Smith, L., Haro, J. M., \& Koyanagi, A. (2020). Fast food consumption and suicide attempts among adolescents aged 12-15 years from 32 
countries. Journal of Affective Disorders, 266, 63-70. https://doi.org/10.1016/j.jad.2020.01.130

Jamal, A., Phillips, E., Gentzke, A. S., Homa, D. M., Babb, S. D., King, B. A., \& Neff, L. J. (2018). Current cigarette smoking among adults - United States, 2016. Morbidity and Mortality Weekly Report, 67(2), 53. https://dx.doi.org/10.15585\%2Fmmwr.mm6702a1

Kalman, M., Inchley, J., Sigmundova, D., Iannotti, R. J., Tynjälä, J. A., Hamrik, Z., ... \& Bucksch, J. (2015). Secular trends in moderate-to-vigorous physical activity in 32 countries from 2002 to 2010: A crossnational perspective. The European Journal of Public Health, 25(2), 37-40. https://doi.org/10.1093/eurpub/ ckv024

Katzmarzyk, P. T., Denstel, K. D., Beals, K., Carlson, J., Crouter, S. E., McKenzie, T. L., ... \& Wright, C. (2018). Results from the United States 2018 report card on physical activity for children and youth. Journal of Physical Activity and Health, 15(s2), 422-424. https:// doi.org/10.1123/jpah.2018-0476

Kessler, R. C., Barker, P. R., Colpe, L.J., Epstein, J. F., Gfroerer, J. C., Hiripi, E., Zaslavsky, A. M. (2003) Screening for serious mental illness in the general population. Archives of General Psychiatry, 60, 184189, doi:10.1001/archpsyc.60.2.184.

Khouja, J. N., Munafò, M. R., Relton, C. L., Taylor, A. E., Gage, S. H., \& Richmond, R. C. (2020). Investigating the added value of biomarkers compared with selfreported smoking in predicting future e-cigarette use: Evidence from a longitudinal UK cohort study. PloS One, 15(7), e0235629. https://doi.org/10.1371/journal. pone.0235629

Koa, S. H., \& Parkb, C. (2020) Predictors analysis of physical activity participation among young adults. International Journal of Innovation, Creativity and Change, 13(3), 557-569.

Martins, J., Marques, A., Peralta, M., HenriquesNeto, D., Costa, J., Onofre, M., \& Valeiro, M. G. (2020). A comparative study of participation in physical education classes among 170,347 adolescents from 54 low-, middle-, and high-income countries. International Journal of Environmental Research and Public Health, 17(15), 5579. https://doi.org/10.3390/ijerph17155579

Mayo, C. D., Miksche, K., Attwell-Pope, K., \& Gawryluk, J. R. (2019). The relationship between physical activity and symptoms of fatigue, mood, and perceived cognitive impairment in adults with multiple sclerosis. Journal of Clinical and Experimental Neuropsychology, 41(7), 715-722. https://doi.org/10.10 $80 / 13803395.2019 .1614535$

Mieziene, B., Emeljanovas, A., Fatkulina, N., \& Stukas, R. (2020). Dietary pattern and its correlates among Lithuanian young adults: Mediterranean diet approach. Nutrients, 12(7), 2025. https://doi.org/10.3390/ nu12072025

Mullane, S. L., Toledo, M. J., Rydell, S. A., Feltes, L. H., Vuong, B., Crespo, N. C., ... \& Buman, M. P. (2017). Social ecological correlates of workplace sedentary behavior. International Journal of Behavioral Nutrition and Physical Activity, 14(1), 117. https://doi.org/10.1186/ s12966-017-0576-x

Niles, M. T., Emery, B. F., Wiltshire, S., Brown, M. E., Fisher, B., \& Ricketts, T. H. (2020). Climate impacts associated with reduced diet diversity in children across nineteen countries. Environmental Research Letters, 16(1), 015010. https://doi.org/10.1088/1748-9326/abd0ab

Nour, M., Sui, Z., Grech, A., Rangan, A., McGeechan, K., \& Allman-Farinelli, M. (2017). The fruit and vegetable intake of young Australian adults: A population perspective. Public Health Nutrition, 20(14), 24992512. https://doi.org/10.1017/S1368980017001124

Novak, D., Štefan, L., Prosoli, R., Emeljanovas, A., Mieziene, B., Milanović, I., \& Radisavljević-Janić, S. (2017). Mediterranean diet and its correlates among adolescents in non-Mediterranean European countries: A population-based study. Nutrients, 9(2), 177. https://doi. org/10.3390/nu9020177

Ogden, C. L., Carroll, M. D., Kit, B. K., \& Flegal, K. M. (2014). Prevalence of childhood and adult obesity in the United States, 2011-2012. Jama, 311(8), 806-814. doi:10.1001/jama.2014.732

Pärna, K. (2020). Alcohol consumption and alcohol policy in Estonia 2000-2017 in the context of Baltic and Nordic countries. Drug and Alcohol Review, 39(7), 797-804. https://doi.org/10.1111/dar.13008

Pedersen, A. L. W., Lindekilde, C. R., Andersen, K., Hjorth, P., \& Gildberg, F. A. (2020). Health behaviours of forensic mental health service users, in relation to smoking, alcohol consumption, dietary behaviours and physical activity - A mixed methods systematic review. Journal of Psychiatric and Mental Health Nursing, 1, 1-18, doi: 10.1111/jpm.12688.

Piepoli, M. F., Hoes, A. W., Agewall, S., Albus, C., Brotons, C., ... \& Zamorano, J. L. (2016). 2016 European Guidelines on cardiovascular disease prevention in clinical practice: The Sixth Joint Task Force of the European Society of Cardiology and Other Societies on Cardiovascular Disease Prevention in Clinical Practice. European Journal of Preventive Cardiology, 23(11), $1-96$.

Sadeghi, O., Keshteli, A. H., Afshar, H., Esmaillzadeh, A., \& Adibi, P. (2019). Adherence to Mediterranean dietary pattern is inversely associated with depression, anxiety and psychological distress. Nutritional Neuroscience, 24(4), 1-12. https://doi.org/10.1080/1028415X.2019. 1620425

Seo, Y. M., Kang, M. S., \& Jeon, M. Y. (2016). Predictive factors on level of physical activity in the community dwelling elderly. Journal of the Korea Convergence Society, 7(6), 151-160. https://doi.org/10.15207/ JKCS.2016.7.6.151

Silva, D. A. S., Chaput, J. P., \& Tremblay, M. S. (2019). Participation frequency in physical education classes and physical activity and sitting time in Brazilian adolescents. PloS One, 14(3), e0213785. https://doi.org/10.1371/journal.pone. 0213785

Substance abuse and mental health services administration. (2018). The National Survey on Drug Use and 
Health. 2017. Available at: https://samhsa.gov/data/sites/ default/files/nsduh-ppt-09-2018.pdf.

Taheri, E., Ghorbani, A., Salehi, M., \& Sadeghnia, H. R. (2015). Cigarette smoking behavior and the related factors among the students of Mashhad university of medical sciences in Iran. Iranian Red Crescent Medical Journal, 17(1), e16769. https://dx.doi.org/10. 5812\%2Fircmj.16769

Teasdale, S. B., Burrows, T. L., Hayes, T., Hsia, C. Y., Watkins, A., Curtis, J., \& Ward, P. B. (2020). Dietary intake, food addiction and nutrition knowledge in young people with mental illness. Nutrition \& Dietetics, 77(3), 315-322. https://doi.org/10.1111/1747-0080.12550

Uddin, R., Burton, N. W., \& Khan, A. (2020). combined effects of physical inactivity and sedentary behaviour on psychological distress among university-based young adults: A one-year prospective study. Psychiatric Quarterly, 91(1), 191-202. https://doi.org/10.1007/ s11126-019-09697-2
Unick, J. L., Lang, W., Tate, D. F., Bond, D. S., Espeland, M. A., \& Wing, R. R. (2017). Objective estimates of physical activity and sedentary time among young adults. Journal of Obesity, 17(1), 1-11. https:// doi.org/10.1155/2017/9257564

Wang, T. W., Asman, K., Gentzke, A. S., Cullen, K. A., Holder-Hayes, E., Reyes-Guzman, C., ... \& King, B. A. (2018). Tobaccoproductuseamongadults - United States, 2017. Morbidity and Mortality Weekly Report, 67(44), 1225. https://dx.doi.org/10.15585\%2Fmmwr.mm6744a2 Ward, D. S., Bower, J. K., Hales, D. P., Tate, D. F., Rubin, D. A., \& Benjamin, S. E. (2008). The childcare environment and children's physical activity. American Journal of Preventive Medicine, 34(1), 23-29. https:// doi.org/10.1016/j.amepre.2007.09.022

World health organization: global report on trends in prevalence of tobacco smoking 2000-2025. (2018). Available at: https://apps.who.int/iris/bitstream/hand le/10665/272694/9789241514170-eng.pdf?ua=1 